\title{
CARACTERÍSTICAS FÍSICAS E QUÍMICAS DE BEBIDAS LÁCTEAS FERMENTADAS E PREPARADAS COM SORO DE QUEIJO MINAS FRESCAL ${ }^{1}$
}

\author{
Keila Emílio de ALMEIDA ${ }^{2}$, Ismael Antonio BONASSI ${ }^{3, *}$, Roberto de Oliveira ROÇA ${ }^{3}$
}

\begin{abstract}
RESUMO
Nesta pesquisa procurou-se verificar as características físicas e químicas de bebidas lácteas preparadas com três concentrações de soro de queijo Minas Frescal (30, 40 e 50\%), empregando-se dois tipos de culturas lácticas: uma tradicional para iogurte (YC-180) contendo cepas mistas de Streptococcus salivarus subsp. thermophilus, Lactobacillus delbrueckii subsp. lactis e Lactobacillus delbrueckii subsp. bulgaricus e outra (ABY-1) contendo cepas mistas de Lactobacillus delbrueckii subsp. bulgaricus, Lactobacillus acidophillus, Bifidobacteria e Streptococcus salivarius subsp. thermophilus. Constatou-se que as bebidas lácteas apresentaram diferença estatística no tempo zero para os teores de gordura e de extrato seco. À medida em que se elevou a proporção de soro em relação ao leite, os teores de gordura e de extrato seco diminuíram. O teor de proteína também diminuiu à medida em que se aumentou o teor de soro nas bebidas lácteas, embora a diferença não tenha sido tão acentuada quanto as observadas para os teores de gordura e de extrato seco. Em relação à lactose, não se constatou diferença entre os tratamentos. Os teores de soro não influenciaram o índice de proteólise das bebidas lácteas. Verificou-se todavia que as bebidas elaboradas com a cultura probiótica ABY-1 apresentaram valores superiores para proteólise quando comparadas às bebidas elaboradas com as culturas YC-180. As bebidas lácteas elaboradas com $30 \%$ de soro apresentaram maiores valores para viscosidade. As bebidas elaboradas com a cultura YC-180 apresentaram valores superiores para viscosidade durante o período de armazenamento.
\end{abstract}

Palavras-chave: bebida láctea fermentada; característica física; característica química; soro de Minas Frescal.

\section{SUMMARY}

PHYSICAL AND CHEMICAL CHARACTERISTICS OF FERMENTED DAIRY BEVERAGES USING MINAS CHEESE WHEY. This research studies the physical and chemical characteristics of dairy beverages formulated with three different concentrations (30, 40 and $50 \%)$ of Minas cheese whey, using two kinds of dairy cultures: the traditional yogurt (YC-180) culture, holding mixed strains of Streptococcus salivarus subsp. thermophilus, Lactobacillus delbrueckii subsp. lactis and Lactobacillus delbrueckii subsp. bulgaricus, and the alternate (ABY-1), holding mixed strains of Lactobacillus delbrueckii subsp. bulgaricus, Lactobacillus acidophilus, Bifidobacteria and Streptococcus salivarius subsp. thermophilus. The dairy beverages showed statistical differences for fat and dry extract contents at zero time. The higher the whey content in relation to milk was, the lower the fat and dry extract content. The protein level also

\footnotetext{
${ }_{1}^{1}$ Recebido para publicação em 17/11/00. Aceito para publicação em 18/04/01.

${ }^{2}$ Aluna do Curso de Pós-Graduação em Agronomia - Área de Concentração em Energia na Agricultura - F.C.A. - Campus de Botucatu - UNESP.

${ }^{3}$ Departamento de Gestão e Tecnologia Agroindustrial - F.C.A.UNESP - Caixa Postal 237, CEP. 18603-970 - Botucatu - SP. E-mail: secdtpa@fca.unesp.br

${ }^{*}$ A quem a correspondência deve ser enviada.
}

decreased as the whey level was increased. This difference, however, was not as remarkable as that for fat and dry extract contents. Concerning lactose, no difference was observed among the treatments. The different whey concentrations did not influence the proteolysis rate. However, beverages prepared using ABY-1 probiotic culture have shown higher values for proteolysis when compared to beverages from YC -180 cultures. The dairy beverages formulated with $30 \%$ whey had higher viscosity values. Beverages prepared using YC-180 culture have shown higher values for viscosity during the storage period.

Keywords: fermented dairy beverage; physical characteristic; chemical characteristic; Minas cheese whey.

\section{1 - INTRODUÇÃO}

Vários trabalhos de pesquisa foram desenvolvidos em diversos países visando criar opções para a utilização do lactossoro, evitando assim que funcione como agente de poluição ambiental devido à sua alta demanda biológica de oxigênio (DBO).

Este subproduto representa de $85-90 \%$ do volume de leite utilizado na fabricação de queijos, retendo ao redor de $55 \%$ dos nutrientes do leite. SISO [21] salientou que $50 \%$ da produção mundial de soro é tratada e transformada em vários produtos alimentares, sendo que deste total quase a metade é usada diretamente na forma líquida.

A utilização de soro de queijo na elaboração de bebidas lácteas constitui-se numa forma racional de aproveitamento deste produto secundário que apresenta excelente valor nutritivo. Como destacam TAMIME [23] e TAMIME \& ROBINSON [24], tem aumentado de maneira notável o consumo dessas bebidas fermentadas que se caracterizam por apresentar baixa viscosidade. Em nosso país, também segundo a ABIQ [1], a produção de bebidas lácteas tem alcançado aumento considerável.

O Regulamento Técnico de Identidade e Qualidade de Bebidas Lácteas [5] especifica que bebida láctea é o produto obtido, a partir de leite ou leite reconstituído e/ou derivados de leite, fermentado ou não, com ou sem adição de outros ingredientes, onde a base láctea representa pelo menos $51 \%(\mathrm{~m} / \mathrm{m})$ do total de ingredientes do produto.

No entanto, a relação leite-soro é um pouco aleatória, não sendo bem definida, não se tendo portanto conhecimento do que pode ocorrer ao se mudar a proporção. Assim, neste trabalho procurou-se estudar relações diferentes da mistura leite-soro resultante da fabricação do queijo Minas Frescal, que é um produto tipicamente nacional. Duas culturas láticas foram utilizadas, a tradicional para iogurte e outra adicionada de microrganismos probióticos. 


\section{2 - MATERIAL E MÉTODOS}

\section{1 - Elaboração das bebidas lácteas}

Foi utilizado leite pasteurizado com teor de gordura padronizado a $3 \%$ e soro de queijo Minas Frescal obtido conforme metodologia especificada em FURTADO \& NETO [10]. Utilizou-se duas culturas láticas termofílicas DVS-50U (Direct Vac Set), obtidas junto à Chr. Hansen Ind. e Com. Ltda: uma tradicional para iogurte (YC-180), contendo cepas mistas de Streptococcus salivarius subsp. thermophilus, Lactobacillus delbrueckii subsp. lactis e Lactobacillus delbrueckii subsp. bulgaricus e outra (ABY-1) contendo cepas mistas de Lactobacillus delbrueckii subsp. bulgaricus, Lactobacillus acidophilus, Bifidobactéria e Streptococcus salivarius subsp. thermophilus. Como estabilizante-espessante foi usado o Dairymix-BL, constituído por mistura de hidrocolóides.

Foram preparadas bebidas lácteas com três concentrações de soro lácteo (30\%, 40\% e 50\%) misturado ao leite. O volume utilizado para elaboração das bebidas foi de $1 \mathrm{~L}$. O mesmo tipo de leite usado para a fabricação do queijo foi utilizado para a preparação da bebida. $\mathrm{O}$ estabilizante foi adicionado às misturas na quantidade de $0,45 \%(p / v)$, sob agitação antes da pasteurização, conforme recomendação do fabricante. As misturas foram colocadas em erlenmeyers e submetidas ao aquecimento de $90^{\circ} \mathrm{C}$ por 3 minutos. Após atingir esse binômio tempo-temperatura, foram resfriadas a $45^{\circ} \mathrm{C}$, com o auxílio de mistura gelo-água, recebendo então o inóculo das culturas láticas. A quantidade de inóculo utilizada na preparação das bebidas lácteas foi de $2 \mathrm{~mL} / \mathrm{L}$ de leite para a cultura $A B Y-1$ e de $1 \mathrm{~mL} / \mathrm{L}$ para a cultura YC-180 conforme indicações de CHR. HANSEN'S [6]. Considerou-se um tempo de 4-4,5 horas de incubação para o abaixamento do $\mathrm{pH}$ até os valores de 5,00 a 4,50.

O volume de $1 \mathrm{~L}$ foi dividido em embalagens plásticas com volume de $200 \mathrm{~mL}$ cada, que foram armazenadas sob refrigeração $\left(4 \pm 1^{\circ} \mathrm{C}\right)$, acompanhando-se a vidade-prateleira dos produtos durante 28 dias.

Foram efetuados quatro processamentos em dias diferentes (quatro experimentos).

\section{2 - Análises físico-químicas e químicas}

O leite e o soro de queijo foram analisados em relação à acidez titulável [2], matéria graxa determinada pelo método de Gerber, segundo SCHMIDT-HEBBEL [20], proteína bruta [2, 4], lactose [13] e extrato seco total [2]. Logo após a fabricação (tempo zero) as bebidas foram analisadas em relação a $\mathrm{pH}$ [3], acidez titulável [2], gordura [20], proteína [2, 4], extrato seco [2] e lactose [13]. A cada sete dias, durante 28 dias, efetuou-se análises de acidez titulável [2], lactose [13] e índice de proteólise.

Como parâmetro para determinação da proteólise avaliou-se o teor de tirosina, segundo o método descrito por HULL [12], com algumas adaptações. Para iní- cio de cada série de análises, o conteúdo das embalagens foi homogeneizado por agitação por cerca de 10 segundos. Um volume de $5 \mathrm{~mL}$ de amostra foi pipetado e adicionado de $10 \mathrm{~mL}$ de TCA $0,72 \mathrm{~N}$ para então ser agitado. A amostra foi deixada em repouso por 10 minutos e então filtrada em papel de filtro Whatman $n^{\circ} 01$. $\mathrm{Em} 5 \mathrm{~mL}$ do filtrado foram adicionados $10 \mathrm{~mL}$ do reagente carbonato tetrafosfato e $3 \mathrm{~mL}$ do reagente de FolinCiocalteau. A mistura foi agitada em agitador magnético e esperou-se um intervalo de 5 minutos. Observouse turbidez no material e a formação de um precipitado branco no fundo dos tubos. O material foi centrifugado por 5 minutos e filtrado novamente em papel de filtro comum. A leitura foi feita em espectrofotômetro a $650 \mathrm{~nm}$.

A viscosidade foi determinada a cada sete dias, durante 28 dias, para acompanhar as possíveis mudanças ocorridas durante a vida-de-prateleira. Utilizouse viscosímetro de Brookfield, modelo LVT, utilizandose haste número 2 e velocidade de $6 \mathrm{rpm}$. As amostras mantidas a $6^{\circ} \mathrm{C}$, foram homogeneizadas antes das análises e os resultados lidos numa escala de 0 a 100 , foram convertidos a centipoise através de tabela apropriada [27].

\section{3 - Análise estatística}

O delineamento experimental adotado para as análises logo após a fabricação foi a de blocos ao acaso. Os resultados foram analisados através da comparação entre as médias dos tratamentos, com a utilização do teste de Tukey nas médias transformadas, estabelecendo que a significância estatística seria ao nível de $5 \%$ de probabilidade, conforme SNEDECOR \& COCHRAN [22]. As análises foram realizadas pelo programa Statistical Analysis System: SAS [18].

\section{3 - RESULTADOS E DISCUSSÃO}

Os valores médios encontrados para composição físico-química e química das bebidas lácteas, encontram-se na Tabela 1.

TABELA 1. Valores médios obtidos para composição físico-química e química das bebidas lácteas.

\begin{tabular}{ccccccc}
\hline \hline & \multicolumn{6}{c}{ Tratamentos } \\
\cline { 2 - 7 } Parâmetro & $30-\mathrm{P}$ & $40-\mathrm{P}$ & $50-\mathrm{P}$ & $30-\mathrm{I}$ & $40-\mathrm{I}$ & $50-\mathrm{I}$ \\
\hline $\mathrm{pH}$ & $5,14 \mathrm{a}$ & $5,08 \mathrm{a}$ & $5,07 \mathrm{a}$ & $4,63 \mathrm{~b}$ & $4,56 \mathrm{~b}$ & $4,61 \mathrm{~b}$ \\
Gordura (\%) & $2,01 \mathrm{a}$ & $1,83 \mathrm{ab}$ & $1,71 \mathrm{ab}$ & $1,92 \mathrm{ab}$ & $1,76 \mathrm{ab}$ & $1,59 \mathrm{~b}$ \\
Proteína (\%) & $2,08 \mathrm{a}$ & $2,08 \mathrm{a}$ & $2,05 \mathrm{a}$ & $2,14 \mathrm{a}$ & $1,97 \mathrm{a}$ & $1,94 \mathrm{a}$ \\
Lactose (\%) & $4,57 \mathrm{a}$ & $4,56 \mathrm{a}$ & $4,53 \mathrm{a}$ & $4,69 \mathrm{a}$ & $4,62 \mathrm{a}$ & $4,66 \mathrm{a}$ \\
Extrato Seco (\%) & $8,71 \mathrm{a}$ & $8,23 \mathrm{~b}$ & $7,78 \mathrm{c}$ & $8,89 \mathrm{a}$ & $8,67 \mathrm{a}$ & $7,86 \mathrm{c}$ \\
\hline \hline
\end{tabular}

- 30, 40 e 50- Bebidas lácteas contendo 30,40 e $50 \%$ de soro; P- bebidas elaboradas com a cultura probiótica ABY-1; I- bebidas elaboradas com a cultura de iogurte YC-180.

- Médias de tratamentos seguidas pelas mesmas letras não diferem entre si pelo teste de Tukey, ao nível de $5 \%$ de significância.

Em relação ao $\mathrm{pH}$, para as bebidas elaboradas com a cultura YC-180, constituída de Lactobacillus delbrueckii subesp. lactis, Lactobacillus delbrueckii subesp. bulgaricus 
e Streptococcus salivarius subesp. thermophilus, manteve-se o $\mathrm{pH}$ em torno de 4,6 conforme proposto por diversos autores $[8,9,15,17]$. No entanto, para as bebidas em que foi utilizada a cultura $A B Y-1$, contendo Lactobacillus acidophilus, Bifidobactéria, Streptococcus salivarius subesp. thermophilus e Lactobacillus delbrueckii subesp. bulgaricus, procurou-se manter o $\mathrm{pH}$ acima de 5,00 , pois segundo SCARDOVI [19], algumas espécies de bifidobactéria não se desenvolvem em pH entre 4,50 e 5,00. Neste sentido, foi observada diferença significativa entre as bebidas lácteas elaboradas com a cultura probiótica $A B Y-1$ e com a cultura de iogurte YC180, conforme pode ser observado na Tabela 1.

Para gordura, pode-se observar que houve diferença estatística entre os tratamentos. À medida em que se elevou a proporção de soro em relação ao leite, o teor de gordura diminuiu. Isto pode ser explicado tendo em vista que o teor de gordura do leite foi cinco vezes superior ao teor encontrado no soro $(3,00 \%$ vs $0,60 \%)$. OTERO et al [16] estudaram bebidas lácteas feitas com leite diluído em soro de queijo e água. Verificaram que os valores médios de gordura encontrados para as bebidas elaboradas com soro foram ligeiramente superiores aos elaborados com água.

A diferença entre os teores de proteína nas bebidas lácteas não foram tão acentuadas quanto as observadas para o teor de gordura, pois embora tenha-se verificado diminuição no teor de proteína à medida em que se aumentou a quantidade de soro nas bebidas lácteas, esta diferença não foi estatística.

Quanto à lactose, não se constatou diferença significativa entre os tratamentos. O teor de lactose do soro utilizado $(4,50 \%)$ na preparação das bebidas lácteas foi semelhante ao do leite $(4,30)$.

Observou-se que os valores médios obtidos para extrato seco apresentaram diferença significativa entre os tratamentos. Essa diferença se deve ao fato da utilização de diferentes teores de soro nas misturas, pois o teor de extrato seco do leite foi duas vezes maior que o do soro de queijo. Esta diferença influenciou o teor de extrato seco encontrado em cada bebida láctea elaborada com os diferentes teores de soro. As bebidas com $30 \%$ de soro apresentaram maiores valores de extrato seco.

Não se observou diferença estatística significativa entre as bebidas lácteas preparadas com a cultura probiótica ABY-1 e com a cultura de iogurte YC-180 para as mesmas proporções de soro utilizadas.

As Figuras 1 a 8 ilustram a variação de lactose, acidez titulável, índice de proteólise e viscosidade a cada 7 dias, durante 28 dias, para as bebidas elaboradas com as culturas ABY-1 e YC-180.

Observando-se as Figuras 1 e 2, nota-se que os tratamentos elaborados com os dois tipos de cultura parecem não diferir no que diz respeito à metabolização de lactose durante o período de armazenamento. Consumo maior foi observado no período inicial, que compreende os 14 primeiros dias. TOBAT, WATANAGE,
ADACHI [25] mostraram que paralelamente à degradação da lactose no iogurte, há aumento na concentração da galactose. Neste trabalho foi observado que ocorre inicialmente aumento e posterior diminuição da glicose, formação de oligossacarídeos, queda do $\mathrm{pH}$ e aumento na acidez titulável durante sua incubação e armazenamento. (Figuras 3 e 4 ).

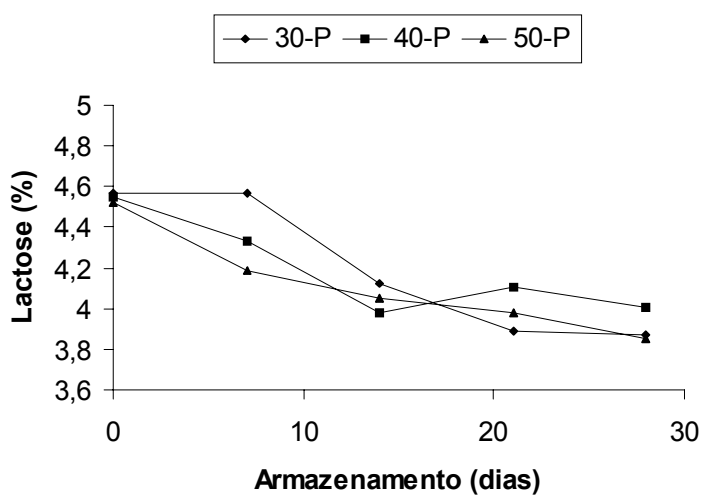

FIGURA 1. Valores médios obtidos para variação da lactose nas bebidas elaboradas com a cultura probiótica ABY-1 durante o período de armazenamento (28 dias).

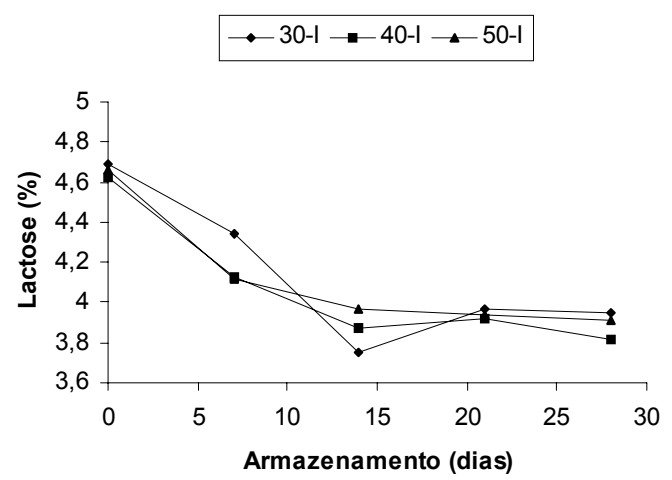

FIGURA 2. Valores médios obtidos para variação da lactose nas bebidas elaboradas com a cultura de iogurte YC-180 durante o período de armazenamento (28 dias).

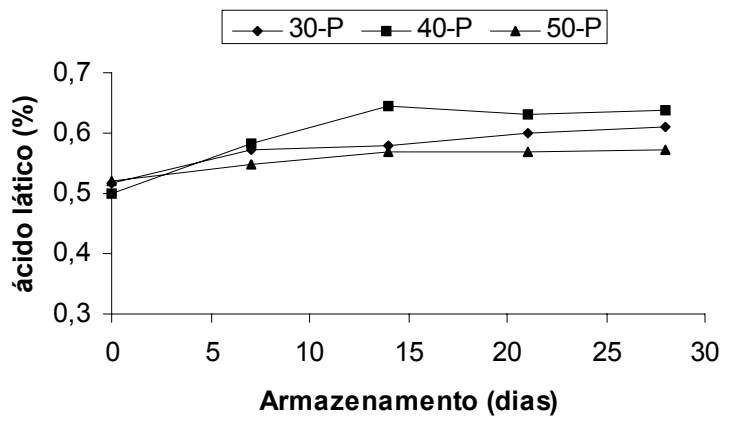

FIGURA 3. Valores médios obtidos para variação da acidez nas bebidas elaboradas com a cultura probiótica ABY-1 durante o período de armazenamento (28 dias). 


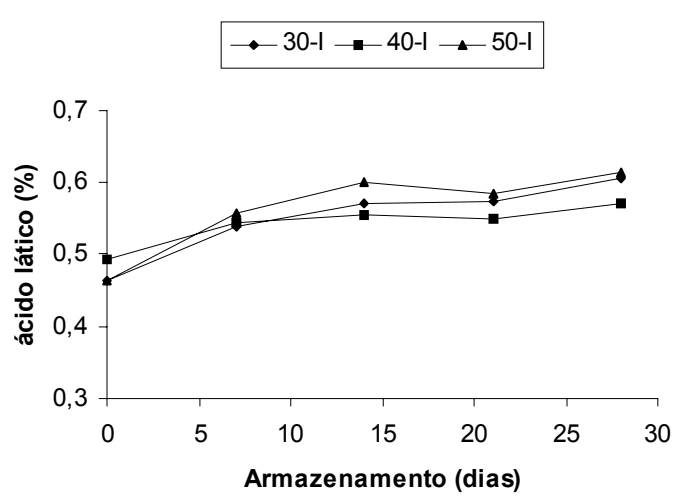

FIGURA 4. Valores médios obtidos para variação da acidez nas bebidas elaboradas com a cultura de iogurte YC-180 durante o período de armazenamento (28 dias).

Pela análise das Figuras 3 e 4, verificou-se que a acidez média aumentou em todos os tratamentos durante o período de armazenamento. Segundo DAVE \& SHAH [7], o Lactobacillus delbrueckii ssp. bulgaricus produz ácido lático durante o armazenamento refrigerado, fenômeno este conhecido como pós acidificação. $\mathrm{KIM}$ et al [14] relataram que quando o L. bulgaricus é excluído da fermentação, o aumento da acidez é reduzido significativamente durante o armazenamento.

Tendência semelhante foi observada por WOLFSCHOON-POMBO, GRANZINOLLI, FERNANDES [27], em iogurtes elaborados com diferentes teores de sólidos totais. Estes autores observaram também que, em função do aumento de sólidos totais, a acidez titulável aumentou nitidamente, o que não foi observado neste trabalho, nas diferentes proporções soro-leite utilizadas para elaboração das bebidas lácteas. Os tratamentos que utilizaram a cultura contendo $L$. acidophilus e bifidobactérias apresentaram acidez ligeiramente superior ao final do período de armazenamento.

Analisando-se todos os tratamentos, verificou-se que, de modo geral, durante os sete primeiros dias de armazenamento, a acidez aumentou de maneira mais acentuada que nos períodos subseqüentes. Essa tendência pode ser explicada pelo fato de que talvez a cultura tenha entrado em declínio por causa da acidez do meio.

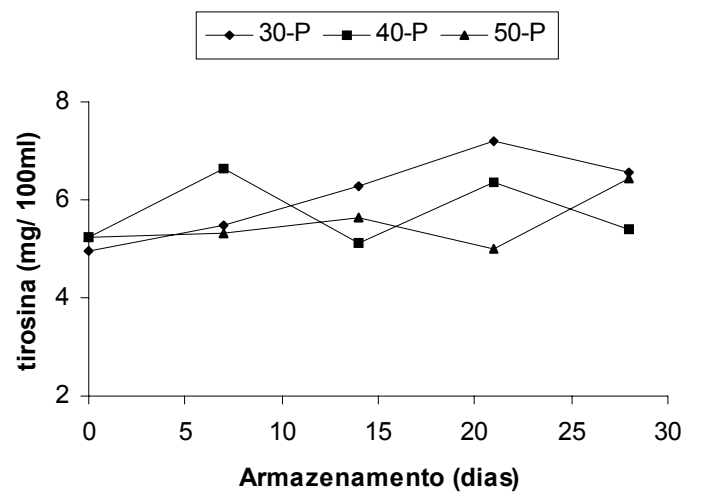

FIGURA 5. Valores médios obtidos para variação da proteólise nas bebidas elaboradas com a cultura probiótica ABY-1 durante o período de armazenamento (28 dias).

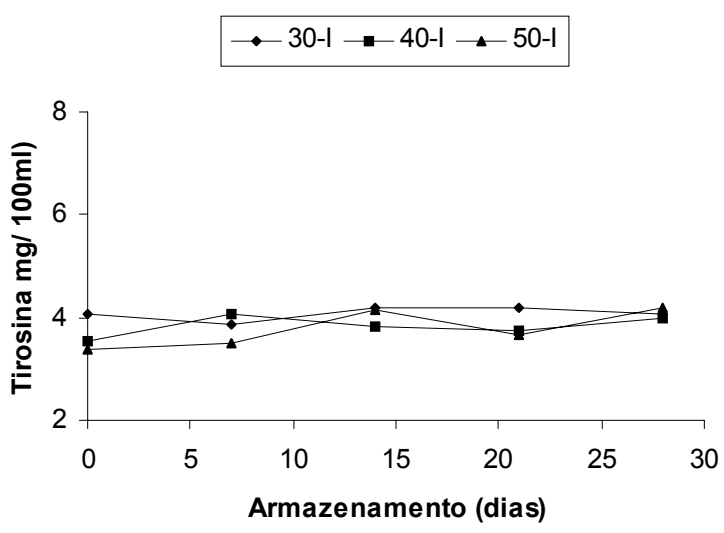

FIGURA 6. Valores médios obtidos para variação da proteólise nas bebidas elaboradas com a cultura de iogurte YC-180 durante o período de armazenamento (28 dias).

Constatou-se que os diferentes teores de soro nas bebidas não influíram no índice de proteólise das bebidas lácteas.

Conforme apresentado nas Figuras 5 e 6, pode-se observar que as bebidas elaboradas com a cultura contendo microrganismos probióticos apresentaram índices de proteólise superiores aos obtidos naquelas elaboradas unicamente com a cultura de iogurte. DAVE \& SHAH [7] afirmaram que o L. acidophilus apresenta atividade proteolítica, fator que beneficia o crescimento de bifidobactéria em produtos fermentados, que requer peptídeos ou aminoácidos derivados da degradação da caseína. TAMIME \& ROBINSON [24], por outro lado, afirmaram que as culturas láticas do iogurte apresentam atividade proteolítica fraca, o que pode ser observado neste trabalho, conforme Figura 6 .

A característica do coágulo é de importância fundamental para a apresentação do iogurte. A viscosidade de um produto é definida como a resistência que o líquido oferece para uma certa força aplicada, sendo dependente de vários aspectos do processo, como: tratamento térmico do leite, condições de incubação e resfriamento, cultura lática utilizada [11].

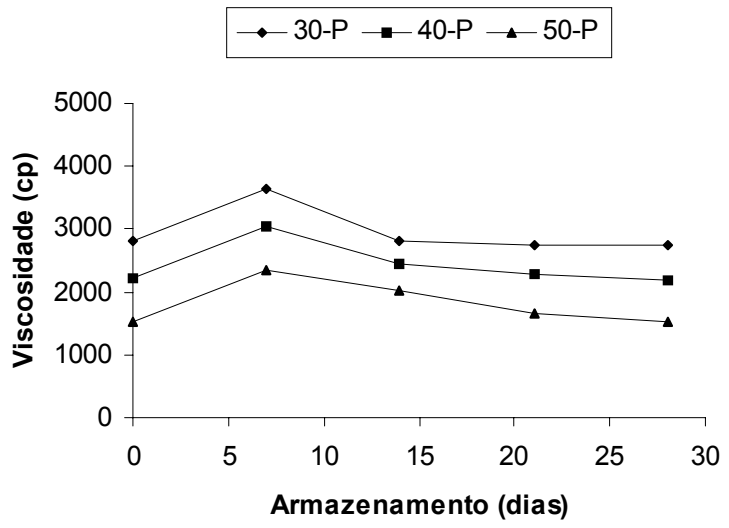

FIGURA 7. Valores médios obtidos para variação da viscosidade nas bebidas elaboradas com a cultura probiótica ABY-1 durante o período de armazenamento (28 dias). 


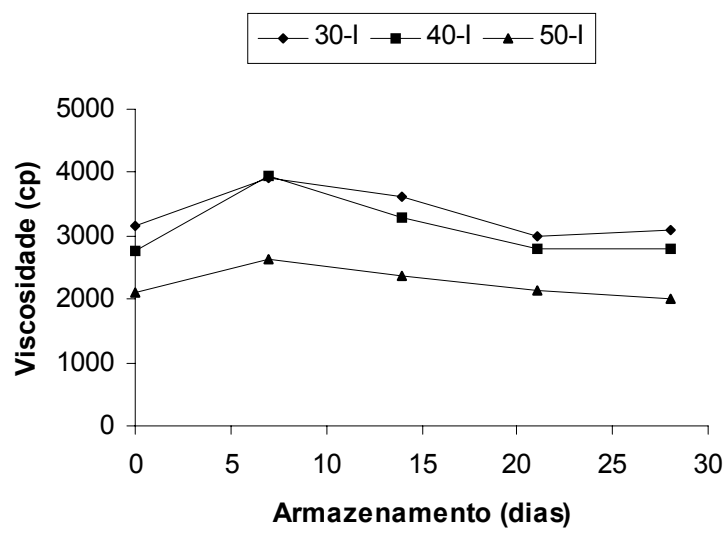

FIGURA 8. Valores médios obtidos para variação da viscosidade nas bebidas elaboradas com a cultura de iogurte YC-180 durante o período de armazenamento (28 dias).

O teor de sólidos influenciou a viscosidade das bebidas lácteas, como observado nas Figuras 7 e 8 . As bebidas elaboradas com $30 \%$ de soro mostraram valores médios maiores para viscosidade. Tendência semelhante foi descrita por WOLFSCHOON-POMBO, GRANZINOLLI, FERNANDES [27], que verificaram que o aumento de sólidos totais ocasionou aumento proporcional na viscosidade do iogurte.

TRINDADE et al [26] também concluíram que o teor de sólidos influiu na viscosidade aparente de iogurtes preparados com leite de soja.

As bebidas elaboradas com a cultura de iogurte YC180 apresentaram valores médios para viscosidade superiores aos da cultura ABY-1. HASHIMOTO \& ANTUNES [11] obtiveram resultados semelhantes, pois segundo estes autores, a cultura YC-180 é considerada filante e apresentou valores superiores para viscosidade, quando comparada a uma cultura não filante. Os autores salientaram ainda que a produção de material extra-celular pela cultura lática filante desempenha importante papel na obtenção de iogurte com firmeza e viscosidade aumentadas.

\section{4 - CONCLUSÕES}

- As bebidas lácteas apresentaram diferença estatística no tempo zero para teores de gordura e extrato seco. À medida em que se elevou a proporção de soro em relação ao leite, os teores de gordura e de extrato seco diminuiram.

- O teor de proteína diminuiu à medida em que se aumentou a quantidade de soro nas bebidas lácteas, embora a diferença não tenha sido tão acentuada quanto às observadas para os teores de gordura e extrato seco.

- Em relação à lactose, não se constatou diferença significativa entre os tratamentos.

- Os diferentes teores de soro não influiram no índice de proteólise das bebidas lácteas. Verificou-se todavia que as bebidas lácteas elaboradas com a cultura probiótica ABY-1 apresentaram valores superiores para proteólise quando comparadas às bebidas elaboradas com a cultura YC-180.

- $\quad$ O teor de sólidos influenciou a viscosidade das bebidas lácteas, sendo que as bebidas elaboradas com $30 \%$ de soro obtiveram valores maiores. As bebidas elaboradas com a cultura YC-180 apresentaram valores superiores para viscosidade durante o período de armazenamento.

\section{5 - REFERÊNCIAS BIBLIOGRÁFICAS}

[1] ASSOCIAÇÃO BRASILEIRA DAS INDÚSTRIAS DE QUEIJO. Dados de Produção Brasil em toneladas de produtos lácteos -1998. ABIC: São Paulo, 1999. (consulta pessoal).

[2] ASSOCIATION OF OFFICIAL ANALYTICAL CHEMISTS. Official Methods of Analysis. 14.ed. Washington, 1984. $1141 \mathrm{p}$.

[3] ATHERTON, H.V.; NEWLANDER,J.A. Chemistry and testing dairy products. 4. Ed. Westport: AVI, 396P, 1981.

[4] BAILEY, J.L. Miscellaneous analytical methods. In: Techniques in protein chemistry. 2.ed. Amsterdan: Elsevier, 1967. cap. 11, p.340-52.

[5] BRASIL. Ministério da Agricultura. Regulamento da Agricultura e do Abastecimento, Regulamento técnico de identidade e qualidade de bebidas lácteas. DAS/SIPOA. Diário Oficial da União, Brasília n²34, p.46-49, 08 de dezembro de 1999. Seção I.

[6] CHR. HANSENS'S. Nutrish Cultures. Denmark: Chr. Hansen's Laboratorium, s.d., 31p.

[7] DAVE, R. I.; SHAH, N. P. Ingredient supplementation effect son viability of probiotic bacteria in yogurt. Journal of Dairy Science, v.81, n.11, p.2804-25, 1998.

[8] DAVE, R.I.; SHAH, N.P. Effect of level of starter culture on viability of yogurt and probiotic bacteria in yogurts. Food Australia, v.4, n.49, p.164-8, 1997.

[9] DODDS, P. Whey Beverage Technology. Cultured Dairy Products Journal, v.54, n.3, p.17-20, 1989.

[10] FURTADO, M.M.; NETO, J.P.M. Tecnologia de QueijosManual Técnico para Produção Industrial de Queijos. 1.ed. São Paulo: Dipemar,1994. 118p.

[11] HASHIMOTO, E.M.; ANTUNES, L.A.F. Efeito do tratamento térmico e de culturas filantes nas características reológicas do iogurte do leite de cabra. Ciênc. Tecnol. Aliment., v. 3, n.15, p.255-61, 1995.

[12] HULL, M.E. Studies on milk proteins. II. Colorimetric determination of the partial hydrolysis of the protein in milk. Journal of Dairy Science, v.30, n.11, p.881-4, 1947.

[13] INSTITUTO ADOLFO LUTZ. Normas Analíticas do Instituto Adolfo Lutz: Métodos químicos e físicos para análise de alimentos. 3.ed. São Paulo: Imprensa Oficial do Estado de São Paulo, 1985. v.1, 533p.

[14] KIM, E.R.; LEE, K.W.; PARK, Y.H.; KWAK, H.S. The study of lactic acid bacteria in yogurt during delivery and storage. Korean Journal of Dairy Science, v.14, n.3, p.260-8, 1993.

[15] LANKAPUTHRA, W.E.V.; SHAH, N.P. Improving viability of Lactobacillus acidophilus and bifidobacteria in yogurt using two step fermentation and neutralised mix. Food Australia, v. 8, n. 49, p. 363-6, 1997.

[16] OTERO, M.; RODRIGUEZ, T.; CAMEJO, J.; CARDOSO, F. Bebida láctea fermentada. Alimentaria, v.32, n.260, p.93-5, 1995. 
[17] SABOYA, L.V.; OETTERER, M.; OLIVEIRA, A.J. Propriedades profiláticas e terapêuticas de leites fermentados- uma revisão. Boletim da SBCTA, v. 2, n. 31, p.176-85,1997.

[18] SAS User's procedures guide. Version 6. 4. ed. Vol.1-2, Cary, NC:SAS Institute, Inc, 1989. 1686p.

[19] SCARDOVI, V. Genus Bifidobacterium Orla-Jensen 1924,472 ${ }^{\mathrm{AL}}$. In: BERGEY'S Manual of systematic bacteriology. Baltimore: Williams \& Wilkins, 1986. V.2, p. 1418-34.

[20] SCHMIDT-HEBBEL, H. Quimica y tecnologia de los alimentos. Santiago: Editorial Salesiana, 1956. 313p.

[21] SISO, M. I. G. The biological utilization of cheese whey: a rewiew. Bioresource Technology, v.57, p.1-11, 1996.

[22] SNEDECOR, G.W.; COCHRAN, W.G. Statistical methods. 6.ed., Ames: lowa State University Press, 1978. 593p.

[23] TAMIME, A.Y. Culturas "starters" lácticas e probióticas. Leites fermentados e bebidas lácticas: tecnologia e mercado, ITAL, Campinas, p.2.11-2.22, 1997.

[24] TAMIME, A.Y.; ROBINSON, R.K. Yogur Ciência y Tecnologia, Zaragoza, Acribia, 1991. 368p.
[25] TOBAT, T.; WATANAGE, A.; ADACHI, S. Quantitative changes in sugar, especialy oligosacharides, during fermentation and storage of Yogurte. Journal Dairy Science,v.6, n.1, p.7-20, 1983.

[26] TRINDADE, C.S.F.; CASCARDO SILVA,F.; FREITAS, S.; COURY, S. Comportamiento reologico de los yogurts de soya homogenizados y no homogenizados. Alimentaria, p.69-73,1997.

[27] WOLFSCHOON-POMBO, A.F.; GRANZINOLLI, G.G.M.; FERNANDES, R.M. Sólidos totais do leite, acidez, pH e viscosidade do iogurte. Revista do Instituto de Laticínios Cândido Tostes, v. 227, n. 37, p.19-24, 1983.

\section{6 - AGRADECIMENTOS}

À Fundação de Amparo à Pesquisa do Estado de São Paulo (FAPESP), pela bolsa de estudos outorgada ao primeiro autor, para realização de seus estudos de mestrado e auxílio financeiro. 